\title{
Responding to COVID-19: What's the Problem?
}

\author{
Roderick J. Lawrence 1
}

Published online: 5 June 2020

(C) The New York Academy of Medicine 2020

\begin{abstract}
This commentary argues that the coronavirus SARS-CoV-2 pandemic should be considered as a transdisciplinary societal challenge that requires coordinated systemic thinking and actions in the context of uncertainty. Responses to the propagation of the coronavirus SARS-CoV-2 and the health, economic and social impacts of Covid-19 are complex, emergent and unpredictable. We describe the virtuous relations between three prerequisite conditions - multilevel governance, knowledge and types of resources and individual and collective behaviours - that should be combined in transdisciplinary responses.
\end{abstract}

First, multi-level governance of this global pandemic is fundamental. At the outset, we challenge political and public scepticism illustrated by the incapacity of politicians and laypeople to listen and learn from scientific knowledge and professional know-how in the context of uncertainty and vulnerability. Governance denotes the way that governments, public administrations, private enterprises and community associations interpret the pandemic, and how they decide collectively to respond to it. In order to reduce known unknowns about this beta-type coronavirus with species jump, the coordinated synthesis of interdisciplinary information and knowledge, professional know-how and individual and social perceptions and understandings are necessary. Then this

R. Lawrence $(\bowtie)$

Geneva School of Social Sciences (G3S), University of Geneva, Geneva, Switzerland

e-mail: roderick.lawrence@unige.ch broad understanding can be applied to define the appropriate allocation of many types of resources (e.g. administrative, financial, human, material, medical, pharmaceutical and scientific) necessary to implement effective responses (see Fig. 1). In contrast to South Korea and Taiwan, many European countries have reacted by following the propagation of this coronavirus rather than being proactive to prevent it despite the warnings made by scientists from 2004 [1]. The contrasting responses of federal/national, state/regional and city/local authorities between and within countries, since January 2020, illustrate how differently this real-world challenge has been interpreted; for example, comparisons between cities in the Lombardy and Veneto regions in northern Italy highlight successes and shortcomings that can be interpreted as lessons learned [2].

Several types of resources coexist for coordinated action and systemic responses to this extraordinary situation: administrative, behavioural, financial, health care, legal and medical resources, and have been used at different geo-political levels, sometimes in an uncoordinated fashion of 'winner takes all'. Notably, some actions have been endorsed by the World Health Organization (e.g. confinement, quarantine, distancing, testing, washing hands) whereas others have not (e.g. wearing masks in public spaces). The diverse interpretations and responses of governments and public administrations confirm that 'evidence-based policy' is a theoretical concept that is often not applied in current circumstances (like many others including ambient air pollution and passive tobacco smoking). Notably, some local authorities in American and European cities have not 
Fig. 1 Effective responses to the complexity, emergence and uncertainty of coronavirus SARSCoV-2 and the compound nature of health, economic and social impacts of COVID-19 require understanding and implementing the virtuous relations between disciplinary knowledge and professional know-how, several types of resources, coordinated multi-level governance, and individual and collective behaviours that should be combined in transdisciplinary contributions.

(C) Roderick Lawrence

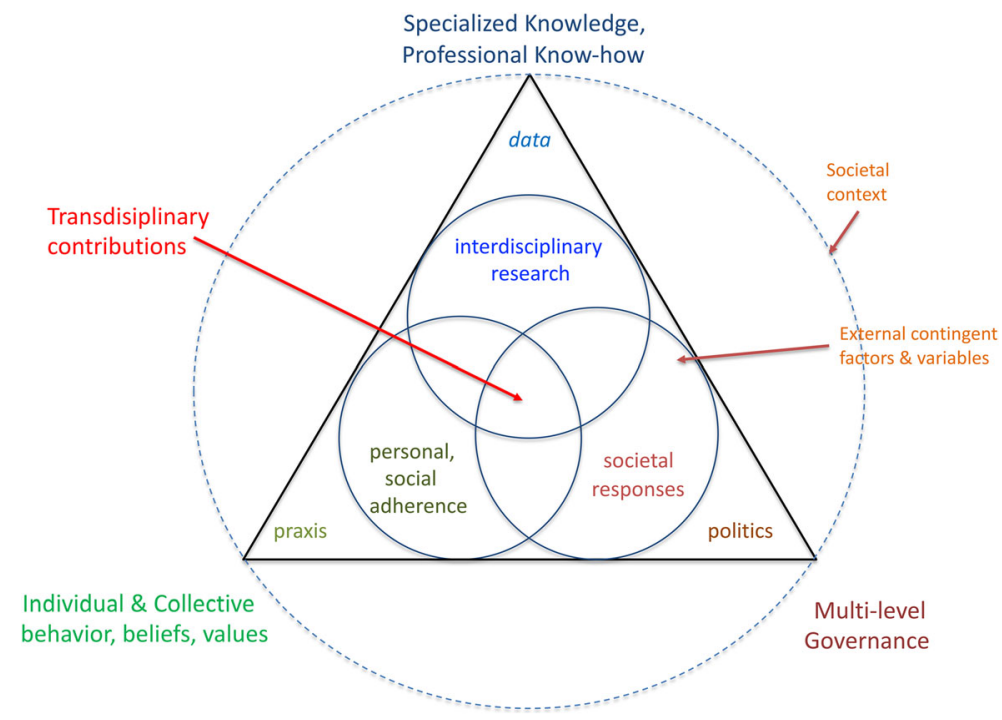

introduced systematic testing and proactive tracing, or legally binding measures, to protect population health.

The second prerequisite condition is the importance of specialised data, information, knowledge and professional know-how required to understand and counteract a new virus for which there is still no proven medical or pharmaceutical remedy. The known unknowns about this coronavirus can be identified and studied using principles of One health, Ecological public health, and Planetary health during transdisciplinary research and practice in community settings to "collect facts on the ground' beyond the walls of laboratories [3]. The nonlinear, uncertain and unpredictable characteristics of this coronavirus are derived from the evolving interfaces between natural ecosystems and human-made environments that accommodate people and all other living organisms that may be vectors of zoonoses including this coronavirus. These novel situations, created by rapid urbanisation in cities and mega-urban regions, can be analysed by interdisciplinary case studies of the multiple consequences of rapid urbanisation. These transdisciplinary case studies should combine biological, epidemiological, medical and veterinary research together with methods of behavioural and social science research.

In addition to knowledge and know-how acquired from biological, ecological, health, medical and veterinary sciences, this pandemic confirms the crucial function and contribution of access to many types of resources when they are needed; in particular, sufficient stocks of medical equipment; hospital wards with specialised infrastructure; replenished supplies of pharmaceutical products; adequate numbers of trained and qualified medical doctors, nursing staff and auxiliary personnel in hospitals, medical centres and nursing homes for elderly persons and coordinated uses of all these resources when the virus is first diagnosed in specific localities. We now know from experience in Asian countries and Italy that the timing of responses to the first diagnosis of this virus in specific cities, and mega-urban regions, is crucial for the effectiveness of counter-measures. The comparison and stark contrast between interventions and resources in Asian cities, including Seoul, Taipei and Singapore, compared with London and New York, is a timely reminder that anticipation by proactive thinking, and preemptive measures by prospective planning, vary considerably between countries and cities irrespective of their GDP or political regime. The Asian cities learned important lessons from the coronavirus SARS-CoV-1 in 2002-2003, which impacted more than 28 countries, highlighting the fundamental contribution of preemptive measures founded on empirical knowledge. Also, national and city comparisons confirm the vital contribution of strategic public health policies after a global shift towards the privatisation of medical and health care services in the last three decades in many countries. Ironically, many advocates of laissez-faire and neo-liberal economics now expect governments to intervene to support private enterprises that are financially fragile or bankrupt, 
including those that failed to provide much needed medical and pharmaceutical equipment currently imported from foreign countries [4].

The third prerequisite condition that influences effective national, city and communal responses to counteract the transmission of coronavirus concern individual, household and community adherence to behavioural norms and new regulations introduced by national and local governments. Some interventions by governments and public administrations concern regulating personal behaviour and interpersonal contacts. For example, norms and rules include different degrees of confinement, controlled access to outdoor public spaces, markets and shops, social distancing, wearing masks and washing hands. Public adherence to these norms and rules cannot be assumed owing to cultural, social and psychological reasons including religious customs, spiritual beliefs, group identity and the notion of individual liberty. Diverse individual and group perceptions of health risks attributed to coronavirus coexist in societies that have endorsed the supremacy of individualism at the expense of collectivism, the authority of Divine providence and rights of humans above all other living organisms on Earth. In this context of heterogeneous lifestyles, values and worldviews, appropriate data and information should be effectively communicated to target groups in order to create responsible behaviour not only for individual health, or social well-being, but also for the common good. We now know there are crucial compromises and trade-offs between individual liberty and personal responsibility, as well as fundamental collective choices about how to respond to economic, health and social threats in the context of uncertainty and vulnerability.

We also know that a patient-centred strategy that targets highly vulnerable individuals and groups should be complemented by a community-centred approach. The negative impacts of this pandemic confirm a wellknown correlation between socioeconomic inequalities and mortality rates of populations at national, regional and city levels [5]. While targeting populations should identify and respond to the needs of vulnerable groups, this pandemic confirms that an area-based approach in countries and cities is also pertinent (e.g. Wuhan in the province of Hubei, China; Bergamo and Lodi in the province of Lombardy, Italy). This dual approach, often used in environmental health interventions, underlines the importance of working with an in-depth understanding of the contextual conditions in which the coronavirus has been diagnosed. Normative behavioural codes and rules should not ignore the societal context including inter- and intra-urban differences. Notably, a WHO recommendation to wash hands repeatedly is unrealistic for all those people (an estimated 790 million people, $11 \%$ of the world's population) who do not have access to a supply of affordable, clean and safe water [6].

This brief commentary confirms that our livelihood and our health are strongly influenced by the biological, ecological, financial, political and cultural milieu in which we live. This milieu, our habitat, and our livelihoods, are founded on fundamental monetary and nonmonetary values. The extraordinary situation of the current pandemic should be a catalyst for rethinking the hierarchy of priorities and values used implicitly and explicitly to sustain our societies. The capacity of public authorities, private enterprises, scientists, practitioners and community associations to respond effectively to major public health threats, such as this coronavirus, should be founded on in-depth understanding of the medical, veterinary and societal variables that influence health and quality of life in specific cities. There are significant differences between health impacts in Geneva and Zurich, Switzerland; or between Adelaide and Sydney in Australia; or between Boston and New York City in the USA, and these differences need deciphering. In each city, a dual temporal perspective should be used to understand its particularities. Initially, short-term responses should respond to patients and curtailing the transmission of the virus within and between cities and countries. This immediate response should be supplemented by mid- and long-term responses founded on strategic actions initiatives that reduce health and economic vulnerability.

The growing number of accounts of the impacts of coronavirus in countries and cities north and south of the Equator presented by the mass media in recent weeks highlights the shortcomings of neo-liberal economics and the fragility of human life in a world that has been transformed by rapid globalisation and urbanisation. These ongoing processes around the globe have reduced the resilience of many countries and cities to counteract global threats because they have lost their capacity to act autonomously after becoming subservient to global production processes and trade with foreign countries in international markets (e.g. dependent on imported face masks, pharmaceutical products and ventilators from abroad to meet national demand). Some wealthy 
countries, including Switzerland, rely heavily on foreign medical and nursing staff to efficiently operate public and private hospitals. Surprisingly, some national governments have reacted by reintroducing controls at national borders, which has been ineffective in limiting the propagation of the pandemic to over 210 countries, and the transmission of the virus-provoking excess mortality in countries. Global governance is not possible if some countries do not comply with international agreements [7]. These expressions of nationalism and sovereignty ignore that a global pandemic cannot be contained by closing national borders.

The main focus of discussion in European and other countries about the impacts of this pandemic on national economies has concentrated on lower production and consumption (GDP) in 2020, the need for public financial support to maintain private enterprises affected by the pandemic, and grants for employees in the formal sector who have become unemployed. The absence of attention to the impacts of this coronavirus on people working in the informal sector reinforces the lack of concern about health impacts of workers in all sectors (including formal health services, and personal care and welfare) [8]. It is unrealistic for workers to respect behavioural codes and rules that ignore that person-toperson contact is the basis on which daily work and income depend. Media reports indicate that many workers, including doctors and nurses in hospitals and nursing homes, do not have the personal equipment necessary to protect them.

Finally, public anxiety about this situation, supported by mass media and social networking, should raise major concerns about the quality of life and resilience of all peoples that can be influenced by major ecological threats (e.g. climate change and extreme weather events); economic instability (since 2008 in many countries); technological accidents (e.g. Fukushima in 2011) and ongoing civil unrest and warfare in several continents. We need to rethink the real interconnected nature of our lives and the livelihoods of others on Earth in contrast to the false claims for nationalism and protectionism in some countries. Notably, we recall the plight of many victims of hunger and malnutrition that can be avoided by concerted action. We underline here that about 9 million people die of hunger and malnutrition each year, and 3 million of these are children who starve to death while about a third of all food produced is disposed as waste. Likewise, the absurdity of the request for social by staying 'at home' given that not less than 150 million people are declared homeless and 1.6 billion are estimated to live in inadequate housing [9]. The fundamental issue is whether the current pandemic will be a catalyst for collective radical rethinking about the future of 'us and others' in a world that should become more ecologically responsible, more economically just, and more socially equitable for the common good, or a shared quest for returning to 'business as usual'.

\section{References}

1. Weiss RA, McLean AR. Emerging infections: what have we learnt from SARS? Philos Trans Biol Sci. 2004;359(1447): $1137-40$.

2. Gary P. Pisano, Raffaella Sadun, and Michele Zanini, 'Lessons from Italy's response to coronavius' Harvard Business Review (27 March) 2020: https://hbr.org/2020/03 /lessons-from-italys-response-to-coronavirus (accessed 12.04.2020).

3. Allen-Scott LK, et al. Academic institutions and one health: building capacity for transdisciplinary research approaches to address complex health issues at the animal-humanecosystem Interface. Acad Med. 2015;90(7):866-71. https://doi.org/10.1097/ACM.0000000000000639.

4. Gallo A. 'Beware the fragility of the global economy' World Economic Forum, (23 March) 2018 https://www.weforum. org/agenda/2018/03/hurricanes-while-the-sun-shines-howto-survive-the-age-of-financial-fragility/ (accessed 17.04.2020).

5. Galea S, Ettman C, Vlahov D, editors. Urban Health. New York and Oxford UK: Oxford University Press; 2019.

6. Centers for Disease Control and Prevention. 'Global Water, Sanitation, and Health (WASH) ' https://www.cdc. gov/healthywater/global/wash_statistics.html (accessed on 12.04.2020).

7. Roojin Habibi et al. Comment, 'Do not violate the International Health Regulations during the COVID-19 outbreak', Lancet 395 (Issue 10225, Feb. 29) 2020:664-666. https://www.ncbi.nlm.nih.gov/pmc/articles/PMC7133591/0. Accessed 17 Apr 2020.

8. According to the International Labour Organization (ILO), about 2 billion people work informally, most of them in emerging and developing countries. See ILO 'Women and men in the informal economy: A statistical picture' 2018 (3rd). https://www.ilo.org/global/publications/bo 1 '1'oks/WCMS 626831/lang\%2D\%2Den/index.htm. Accessed 17 Apr 2020.

9. United Nations, Department of Economic and Social Affairs, Population Division. World Population Prospects 2019: Highlights (ST/ESA/SER.A/423). New York, 2019.

Publisher's Note Springer Nature remains neutral with regard to jurisdictional claims in published maps and institutional affiliations. 
Roderick Lawrence Dr ès Sciences (EPFL), was nominated Professor in the Faculty of Economic and Social Sciences at the University of Geneva in 1999 . He was promoted to Honorary Professor in October 2015. He was founding director of the Certificate of Advanced Studies in Sustainable Development at the University of Geneva (2003-2015), and Invited Professor at the International Institute for Global Health at the United Nations University (IIGH-UNU) in 2014-2016. He has been a member of the Scientific Advisory Board for Interdisciplinary and Transdisciplinary Research at the Swiss Academy of Sciences (SCNAT) since 2009 . Homepage: https://www.unige. $\mathrm{ch} /$ gedt/membres/roderick-lawrence/. 